\title{
El poder regional a examen: irregularidades y singularidades en los juicios de residencia de Tabasco (1666-1707)
}

Carlos Moreno Amador

Universidad de Sevilla (España) 



\title{
El poder regional a examen: irregularidades y singularidades en los juicios de residencia de Tabasco (1666-1707)
}

\section{The regional power to examination: irregularities and singularities in Tabasco residence trials (1666-1707)}

\author{
Carlos Moreno Amador \\ Universidad de Sevilla (España) \\ carlosmoreno@us.es
}

Fecha de recepción: 11 de noviembre de 2020

Fecha de aceptación: 30 de abril de 2021

\begin{abstract}
Resumen
El principal interés de este trabajo se centra en analizar algunas de las irregularidades y peculiaridades más importantes que los juicios de residencia indianos mantuvieron a lo largo de todo el periodo colonial, como fueron las composiciones, las recusaciones, el acompañamiento de testigos, la actuación desempeñada por el escribano de residencia y la carestía de papel sellado que debía utilizarse en dichos procesos, toda vez que llegaron a condicionar el desarrollo y el resultado de los mismos en no pocas ocasiones. Para tal fin, centraremos el foco de atención en la región de Tabasco, considerando la posibilidad de disponer de una serie de juicios de residencia continuados en el tiempo, que abarcan el periodo 1666-1707.
\end{abstract}

Palabras clave: Juicio de residencia; Tabasco (Nueva España); Irregularidades; Peculiaridades, Composiciones; Siglos XVII-XVIII.

\footnotetext{
Abstract

The main interest of this work be to analyze some of the most important irregularities and peculiarities that kept the residency trials in the Spanish america throughout the colonial period, such as the compositions, the challenges, the accompaniment of witnesses, the action carried out by the notary of residence and the scarcity of
} 
El poder regional a examen... - C. Moreno Amador

sealed paper that should be used in said processes, since they came to condition the development and the result of the same on many occasions. To this end, we will focus our attention on the Tabasco region, considering the possibility of having a series of continuous residency trials during the period 1666-1707.

Keywords: Residence trial; Tabasco (New Spain); Irregularities; Peculiarities; Compositions; 17th-18th centuries.

\section{INTRODUCGIÓN}

Son abundantes los trabajos que, a lo largo del tiempo, han dedicado su atención a analizar de forma exhaustiva los juicios de residencia indianos en toda su amplitud, desde su propia definición, pasando por la estructura de los mismos, estudiando su eficacia como mecanismo de control de las autoridades o su trascendencia como fuente documental.

Poco puede añadirse, ciertamente, a la definición ofrecida por diversos autores sobre esta figura jurídica, además de las reflexiones realizadas con el fin de entender cuáles fueron sus orígenes y el proceso de evolución que los llevó a consolidarse en su variante indiana, así como sobre su estructura o sus motivaciones jurídicas o políticas en el nuevo continente. Obras como El juicio de residencia en Castilla a través de la doctrina jurídica de la Edad Moderna (Collantes de Terán, 1998) o El juicio de residencia en Castilla I. Origen y evolución hasta 1480 (González, 1978) para los antecedentes castellanos; monografías como Ensayo sobre los juicios de residencia (Mojarrieta, 1848) o el clásico Ensayo sobre los juicios de residencia indianos (Mariluz, 1952); y, por supuesto, los trabajos sobre visitas y residencias en Indias de Carlos Molina Argüello (Molina, 1973 y1975), dan buena cuenta de todo lo anteriormente citado.

Igualmente reseñable es el hecho de que en las últimas décadas haya surgido una interesante corriente historiográfica que ha centrado su interés en el estudio de este tipo de fuente judicial desde diversos enfoques metodológicos, como la antropología, algo que ha enriquecido, sin duda, la comprensión de los juicios tanto desde su perspectiva histórica como documental. En ese sentido, pueden referenciarse, entre otros, trabajos como El juicio de residencia como fuente etnográfica: Francisco Briceño, gobernador de Guatemala, 1565-1569 (Jiménez, 1997, pp. 11-22), El estudio de las instituciones del gobierno colonial. Una aproximación etnográfica al juicio de residencia como ritual (Smietniansky, 2012, pp. 1-37), o El juicio de residencia: documento inicial para la reconstrucción de la vida social y profesional de los oidores americanos, siglos XVI-XVIII (Angeli, 2012, pp. 182-196).

Asimismo, el análisis de los juicios como base principal para la reconstrucción de periodos gubernativos en cualquier esfera de la administración indiana han sustentado múltiples investigaciones a lo largo de los últimos años, algo que viene a confirmar la tendencia que venimos refiriendo sobre la importancia que han adquirido 
las residencias como fuente de consulta histórica. Artículos como Un temprano juicio de residencia colonial: el Licenciado Juan Fernández, primer fiscal de la Audiencia de Lima. Investigaciones y Ensayos (Angeli, 2014, pp. 437-457) y Funcionarios ante la justicia: residencias de alcaldes mayores y corregidores ventiladas ante la Audiencia de Guadalajara durante el siglo XVIII (Jiménez, 2009, pp. 81-120), o las obras Juicios de residencia en la provincia de Venezuela. Don Francisco Dávila Orejón Gastón, 1673-1677 (Vaccari de Venturini, 1983) y Gobernar bajo sospecha: estrategias del poder y prácticas corruptas en la alcaldía mayor de Tabasco, 16601716, (Moreno, 2018) resultan una buena muestra de ello.

El hecho de que las residencias no permaneciesen inmutables a través de los siglos, sino que fuesen evolucionando y estuviesen sujetas a determinados cambios a medida que la corona iba despachando nuevas disposiciones y la abundante legislación indiana iba desarrollándose -condicionada en gran parte por la actuación de virreyes, audiencias y el Consejo de Indias, además de por la propia aplicación práctica de dichas leyes en las diferentes regiones-, permitió la institucionalización de determinadas prácticas y características que, según en qué lugares, supusieron un freno a la aplicación de lo que en teoría debiera ser un efectivo sistema de control de autoridades. Ese es el motivo por el cual se ha venido debatiendo, desde hace ya demasiado tiempo, acerca de la eficacia o ineficacia de los juicios de residencia, así como sobre el valor de los mismos como fuente documental.

En ese sentido, últimamente son más las voces que buscan poner el foco de atención en la validez del sistema como mecanismo de observación y vigilancia de la corrupción para los mandatarios de la administración indiana, así como en su importancia como fuente documental, aun en el caso de que el proceso resultase insustancial en lo jurídico, toda vez que brindan al historiador una ingente cantidad de información sobre la conformación política, económica y social del lugar donde era residenciado el funcionario de turno. Un buen ejemplo de ambas corrientes lo ofrecen la obra Debates sobre corrupción en el mundo ibérico, siglos XVI-XVIII (Andújar y Ponce, 2018), o los artículos Corrupción y mecanismos de control en la Monarquía Hispánica: una revisión crítica (Andújar, Feros y Ponce, 2017, pp. 284-311), Crimen corruptionis. Justicia y corrupción en la cultura del ius commune (Corona de Castilla, siglos XVI-XVII) (Garriga, 2017, pp. 21-48) y El valor del Juicio de Residencia como fuente documental: estructura, caracteristicas y peculiaridades. El paradigma de Tabasco en la segunda mitad del siglo XVII (Moreno, 2019, pp. 160-191).

Que el estudio de los juicios de residencia indianos está en boga es algo bastante evidente, algo que se aprecia con relativa facilidad considerando la producción bibliográfica que en los últimos tiempos se ha centrado en su análisis desde múltiples perspectivas. Por ese motivo, con el fin de intentar arrojar aún más luz sobre la temática y conseguir enriquecer el análisis metodológico sobre las residencias indianas, el interés de nuestro trabajo pondrá el foco en analizar 
ciertas peculiaridades e irregularidades que apenas han sido referidas en los estudios previos sobre dicha materia, pero que con demasiada frecuencia presentaban las residencias - las cuales podían condicionar tanto el proceso como el resultado final de las mismas-, basándonos en la revisión de una serie sucesiva de juicios que hemos podido consultar relativos al gobierno de la alcaldía mayor de Tabasco durante el periodo 1666-1707.

\section{PEGULIARIDADES E IRREGULARIDADES EN LOS JUICIOS DE RESIDENGIA DE TABASCO}

Si algo bueno tiene disponer de un listado de residencias tabasqueñas tan extenso y continuado en el tiempo es que nos permite establecer una serie de características propias que destacan sobre aquellas que se presuponen básicas en la mayor parte de los juicios a nivel colonial y las convierten en especiales. Por tanto, siendo conocedores de la estructura general de los juicios de residencia en Indias y de sus características más reseñables, conviene detenerse a examinar algunas de las peculiaridades que mostraron estas residencias en la provincia de Tabasco, ya que se observan con bastante frecuencia, y porque nos aportan información valiosa sobre el funcionamiento de determinados aspectos del gobierno de la región.

Partiendo de esas características generales a las que hacíamos alusión, podemos destacar, también, determinadas irregularidades que se cometieron continuamente durante los juicios, algunas de las cuales, como veremos ahora, llegaron a tornarse en características propias de los pleitos tabasqueños.

\subsection{El juez de residencia como sucesor en la alcaldía mayor y el problema de las composiciones}

Uno de los aspectos más característicos que encontramos en los juicios examinados, y durante todo el marco cronológico que abarca esta investigación, es que el magistrado encargado de tomar dicha residencia era, normalmente, su sucesor en el cargo, tal y como se puede comprobar en el Cuadro 1, algo que, a todas luces, resultaba controvertido. ${ }^{1}$

1 Piña Gutiérrez llega a la misma conclusión, aunque únicamente cita uno de los casos a los que nos referimos. (Piña, 2006, pp. 58-59). 
Cuadro 1. Jueces de residencia en Tabasco $(1660-1716)^{2}$

\begin{tabular}{lll}
\hline \multicolumn{1}{c}{ RESIDENCIADO } & \multicolumn{1}{c}{ JUEZ DE RESIDENCIA } & \multicolumn{1}{c}{ CARGO } \\
\hline Antonio Cabrera & Juan del Águila Gayoso & Sucesor en el cargo \\
\hline Juan del Águila Gayoso & Francisco Maldonado de Tejada & Sucesor en el cargo \\
\hline Francisco Maldonado de Tejada & Miguel Fernández de Rivero & Sucesor en el cargo \\
\hline Miguel Fernández de Rivero & Benito de Noboa y Salgado & $\begin{array}{l}\text { Oidor de Santiago } \\
\text { Audiencia de Guatemala }\end{array}$ \\
\hline Diego de Loyola & Sin datos & --------- \\
\hline Pedro de la Maza de la Peña & Antonio Cueto Bracamonte & Sucesor en el cargo \\
\hline Antonio Cueto Bracamonte & Francisco Benítez Maldonado & Sucesor en el cargo \\
\hline Francisco Benítez Maldonado & Pedro Álvarez de Miranda & $\begin{array}{l}\text { Alcalde mayor de } \\
\text { Chiquimula de la Sierra }\end{array}$ \\
\hline Pedro de Zagarraga & & Sucesor en el cargo \\
\hline Pedro Gutiérrez de Mier y Terán & Mateo de Reigadas y Agüero & Sucesor en el cargo \\
\hline Jerónimo Álvarez del Valle & Sin residencia (fallecido) & ---------- \\
\hline Alonso Felipe de Andrade & Mateo de Reigadas y Agüero & Sucesor en el cargo \\
\hline Mateo de Reigadas y Agüero & Sin residencia (fallecido) & ---------- \\
\hline Juan Francisco de Medina Cachón & Juan Sánchez Andrés & Sucesor en el cargo \\
\hline Juan Sánchez Andrés & Manuel Correa Tamariz & ---------- \\
\hline
\end{tabular}

Y es que muchos de los tratadistas contemporáneos condenaron esta práctica por considerarla nociva para el sistema, argumentando que con ello solo se conseguía que los jueces y sus residenciados llegasen a un acuerdo para ocultar los agravios, tratos y granjerías cometidos por los segundos y así poder continuar con dichos negocios, posteriormente, los nuevos gobernantes, con lo que el proceso de residencia resultaba

2 Como podemos comprobar, la mayoría de los jueces de residencia fueron sucesores en el cargo de alcalde mayor de Tabasco. Los datos los hemos podido obtener, en gran parte, de los propios pleitos de los residenciados, toda vez que en ellos se incluye, justo al inicio del expediente, la comisión entregada a los magistrados para tomar la residencia al alcalde mayor. Sirva como ejemplo la extraída del juicio de Juan del Águila Gayoso. Real Cédula otorgando comisión a Francisco Maldonado de Tejeda, que va proveído por alcalde mayor de la provincia de Tabasco, para que tome residencia a don Juan del Águila Gayoso, su antecesor, y a sus ministros y oficiales, de pedimento del fiscal de su majestad, Madrid, 22 de mayo de 1665. Archivo General de Indias (en adelante AGI), Escribanía de Cámara, 222C; Para el caso de Juan Francisco de Medina Cachón y Juan Sánchez Andrés, de los cuales no tenemos sus juicios de residencia, pudimos localizar en el Archivo General de la Nación de México las comisiones que les fueron entregadas a los magistrados encargados de tomarlas. Real provisión para que se tome residencia a don Juan Francisco de Medina Cachón del tiempo que fue alcalde mayor del partido de Tabasco, cometida a don Juan Sánchez Andrés, alcalde mayor actual, Ciudad de México, 1 de octubre de 1712. Archivo General de la Nación de México (en adelante AGNM), Tierras, vol. 2.949, exp. 74; Real provisión para que se tome residencia a don Juan Sánchez Andrés del tiempo que fue alcalde mayor del partido de Tabasco, cometida a don Manuel Correa Tamariz, Cuidad de México, 11 de abril de 1718. AGNM, Tierras, vol. 2.985, exp. 71. 
estéril. Pese a todo, hasta la primera mitad del siglo XVII fue una práctica corriente, teniendo en cuenta las ventajas que ofrecía el método, en la línea de ahorrar en el nombramiento de magistrados y en gastos derivados del proceso. Además, debido a los bajos salarios que ofrecía el puesto de juez de residencia, tampoco resultaba fácil encontrar personas capacitadas que quisiesen trasladarse a lugares tan alejados con el único propósito de tomar la residencia y regresar acto seguido. Ya en los primeros años del siglo XVII, debido principalmente a diversas críticas emanadas desde la administración indiana, la propia legislación americana comenzó a determinar la prohibición de esta práctica, emitiéndose varias reales cédulas, tanto a Nueva España como a Perú, para indicar que no debían ser nombrados por jueces aquellos que iban a reemplazar en el cargo a los residenciados, aunque su nivel de cumplimiento no fue, con mucho, el deseado. En la segunda mitad de la centuria, la ley 25 del título XV del libro V de la Recopilación de Leyes de Indias, recogiendo algunas de estas disposiciones citadas, prohibía que los corregidores y alcaldes mayores fuesen enjuiciados por sus sucesores, aunque dejaba abierta la vía en casos excepcionales, cuando el encargado de relevar al residenciado era de mucha satisfacción y suficiencia (Mariluz, 1952, pp. 48-54).

Por tanto, se puede afirmar que, pese a que la Corona intentó en repetidas ocasiones que se aceptase su postura negativa respecto a la idoneidad de que el sucesor en un determinado cargo fuese quien ejerciese de juez de residencia, en la práctica las prohibiciones emitidas desde la metrópoli chocaron de frente contra las penurias económicas de la Real Hacienda, que imposibilitaban realizar nombramientos de jueces imparciales.

En el caso de Tabasco, como ya hemos referido, la mayoría de los comisionados para ejercer como magistrados en las residencias fueron, precisamente, sucesores en el cargo. Como se puede comprobar en el Cuadro I, solamente tenemos registradas dos referencias en las que los jueces no ocuparon el puesto posteriormente. En ambos casos fue la Audiencia de México quien realizó los nombramientos y no la Corona, que tenía potestad para hacerlo al ser la alcaldía de designación regia.

El motivo de elegir al oidor Benito de Noboa y Salgado y a Pedro Álvarez de Miranda para tomar residencia a Miguel Fernández de Rivero y Francisco Benítez Maldonado, respectivamente, fue la cercanía de los primeros a la provincia de Tabasco, pues ambos se encontraban en Guatemala, toda vez que la Corona no había determinado comisionar como jueces a los respectivos sucesores. ${ }^{3}$ En otras

3 Comisión a don Benito de Noboa y Salgado, oidor de la ciudad de Santiago, en la Audiencia de Guatemala, para que tome residencia a don Miguel Fernández del Rivero, alcalde mayor de Tabasco, y a sus tenientes ministros y oficiales, Madrid, 8 de julio de 1675. AGI, Escribanía de Cámara, 374B; Comisión a don Pedro Álvarez de Miranda, proveído por alcalde mayor de la provincia de Chiquimula, en las de Guatemala, para que tome residencia a don Francisco Benítez Maldonado, del tiempo que ha servido el puesto de alcalde mayor de la provincia de Tabasco, Madrid, 3 de octubre de 1690. AGI, Escribanía de Cámara, 229C. 
dos ocasiones no se llevaron a cabo las residencias, concretamente en los casos de Jerónimo Álvarez del Valle y Mateo de Reigadas y Agüero, debido al prematuro fallecimiento de ambos alcaldes en el ejercicio de su poder. ${ }^{4}$ Por último, debemos destacar la situación que se vivió en la provincia cuando fue enviado como alcalde mayor don Mateos de Reigadas y Agüero, quien, además, fue designado como magistrado encargado de tomar la residencia de los anteriores tres gobernantes tabasqueños, Pedro de Zagarraga, Pedro Gutiérrez de Mier y Terán y Alonso Felipe de Andrade. Según se desprende de la comisión que le fue otorgada en 1699, su labor se circunscribía a juzgar a Pedro Gutiérrez y a aquellos que hubiesen gobernado anteriormente y estuviesen pendientes de darla. ${ }^{5}$ Sin embargo, debido a la demora de su llegada a América, en 1704, tras haber fallecido Jerónimo Álvarez del Valle en Tabasco y necesitarse una persona que cubriese interinamente el puesto de alcalde mayor, que tuviese experiencia militar para sofocar las invasiones piráticas que sufría la provincia, el virrey Duque de Alburquerque decidía enviar a Alonso Felipe de Andrade a la provincia hasta que llegase Reigadas. ${ }^{6}$ Un año después, el 28 abril 1705, el propio Andrade, que ya se encontraba en Tabasco, recibía una comisión para tomar residencia a sus dos antecesores, Pedro de Zagarraga y Pedro Gutiérrez de Mier y Terán, pese a existir una orden anterior, con el mismo efecto, otorgada a Reigadas. Por ello, la Corona, percatándose del error cometido, emitía una real cédula el 22 de mayo, aclarando que la comisión que tenía validez era la que había recibido dicho Reigadas en 1699 y que Andrade no debía usar la suya si no era por ausencia del primero. ${ }^{7}$

Aparejado a la complicación de las sucesiones en la alcaldía mayor tabasqueña, nos encontramos con el problema de las composiciones, uno de los abusos más criticados por parte los vecinos de las colonias, y que afecta principalmente a la relevancia del juicio de residencia como fuente.

4 Copia del título de alcalde mayor de Alonso Felipe de Andrade, Ciudad de México, 17 de mayo de 1704. AGI, Escribanía de Cámara, 233B; Sentencia del Consejo de Indias sobre el juicio de residencia del sargento mayor don Alonso Felipe de Andrade, Madrid, 17 de agosto de 1709. AGI, Escribanía de Cámara, 233B. En diferentes alegaciones realizadas por dicho Felipe de Andrade hace referencia a la muerte del alcalde que le estaba residenciando, Mateo de Reigadas Agüero, su sucesor en el cargo, durante el desempeño de sus funciones, apenas un año después de haber tomado posesión.

5 Real provisión ordenando a Mateo de Reigadas y Agüero, provisto por alcalde mayor de la provincia de Tabasco, tome residencia al capitán don Pedro Gutiérrez de Mier y Terán y a todos aquellos alcaldes que hubiesen sido de la dicha provincia y no la hubiesen tomado, Madrid, 28 de junio de 1699. AGI, Escribanía de Cámara, 233C.

6 Copia del título de alcalde mayor de Alonso Felipe de Andrade, Ciudad de México, 17 de mayo de 1704, cit.

7 Real cédula para aclarar que don Mateo de Reigadas es quien lleva comisión para tomar las residencias, pese a haber emitido otra comisión a Alonso Felipe Andrade para ello, por ser la de don Mateo la primera, Buen Retiro, 22 de mayo de 1705. AGI, Escribanía de Cámara, 222C. 
En no pocas ocasiones, los elegidos para el cargo, que debían normalmente encargarse de la residencia del antecesor, llegaban a un acuerdo con los residenciados, de tal forma que se establecía una verdadera sociedad de intereses que aseguraba la impunidad de aquellos que debían ser juzgados y quitaba a las residencias su verdadera fuerza (Borah, 2002, p. 41). Resulta evidente que, en la mayoría de los casos, al ser la persona designada para realizar el juicio de residencia el sucesor del residenciado, se facilitaba en gran parte dicho pacto, consiguiéndose sucesiones plácidas que rompían con la teórica disposición de que se cumpliesen los preceptos legislativos y se condenase a los gobernantes por cualquier actuación punible que hubiesen podido tener.

Para el caso de Tabasco, si tenemos en cuenta la tónica general acerca de los pactos alcanzados entre residenciado y juez, cuando éste último era el beneficiario del puesto vacante, que hacían estéril la residencia, a priori los expedientes que hemos podido revisar no deberían recoger ningún tipo de referencia a cargos, castigos ni sentencias desfavorables para los alcaldes salientes, sobre todo considerando que en la mayoría de los casos el juez de residencia terminaba ocupando el cargo que quedaba libre. Sin embargo, en el conjunto de los pleitos analizados apenas encontramos referencias de gobernantes sin amonestaciones, siendo la norma general que los alcaldes fueran juzgados de manera eficaz. Ahora bien, también es cierto que en varios de los juicios se cumplió la premisa del amaño. Y es que, pese a que el enjuiciado salía indemne de cargos, posteriormente los vecinos de la provincia terminaban por delatarlos en las siguientes residencias.

El primero de los casos sobre una composición entre magistrado y residenciado se refleja en el pacto llevado a cabo por el juez de residencia y proveído para el cargo de alcalde mayor, Juan del Águila Gayoso, y su antecesor en el puesto, el sargento mayor Antonio de Cabrera, alcalde interino por la muerte de Diego de Bocanegra en 1660. Uno de los testigos presentados en el juicio de residencia de Cabrera, concretamente el sargento Antonio de Rueda, quien ejercía como defensor de los naturales de la provincia, revelaba la composición a la que habían llegado ambos protagonistas, confirmando que Juan del Águila había declinado llevar a término y condenar las causas pendientes que el residenciado Antonio de Cabrera tenía abiertas con los naturales por las deudas que había contraído con ellos y los excesos que había cometido durante su gobierno. Igualmente, declaraba que el juez de residencia había mandado hacer pregón para que ninguno de los naturales de la provincia se compusiese con el residenciado, toda vez que Cabrera estaba dispuesto a pagarles lo que les había defraudado para evitar ser inculpado. ${ }^{8}$

8 Demanda del sargento Antonio de Rueda, defensor de los naturales, contra Antonio Cabrera por haber realizado repartimientos a los naturales cuando fue alcalde mayor, Nueva villa de Santa María de la Victoria, 20 de octubre de 1666. AGI, Escribanía de Cámara, 222C. 
El segundo caso que hemos podido confirmar sobre el pacto realizado entre un gobernante tabasqueño y el magistrado que debía efectuar su residencia es el que involucró al alcalde mayor Miguel Fernández de Rivero y al juez responsable de la misma, el oidor de la Audiencia de Guatemala Benito de Noboa Salgado. Efectivamente, gracias a las declaraciones de varios testigos en una pesquisa que llevó a cabo el obispo de Chiapas y Soconusco, Marcos Bravo de la Serna Manríquez, para hacer averiguación sobre el proceder de dicho oidor como juez de residencia de Fernández de Rivero, queda patente que ambos oficiales alcanzaron un acuerdo para que el residenciado tuviese un juicio tranquilo y pudiese seguir aspirando a nuevos puestos de representación en el futuro. Según algunos vecinos, el alcalde había entregado al magistrado una cantidad de pesos muy elevada -entre $6.000 \mathrm{y}$ 16.000 pesos según los testimonios- además de 20 cargas de cacao para él y para su hijo, presente en la provincia tras haber acompañado a su padre desde Guatemala. Igualmente, el hijo también había recibido como regalo un corte de vestido y unas piezas de Bretaña, mientras que la mujer de Noboa había sido agasajada con un corte de vestido de tela, pues según su testimonio, teniéndola contenta a ella tendrían contento a su marido. Asimismo, los testigos confirmaron que el escribano había recibido 1.000 pesos por la misma razón. Tales regalos habían permitido, según ellos, que el alcalde mayor tuviese "la residencia de un Santo", pues el magistrado no había permitido a los vecinos presentar demandas ni personarse como testigos contra Fernández de Rivero. Es más, Noboa no llegó siquiera a concluir la residencia en Tabasco, pues abandonó su jurisdicción antes del tiempo establecido para ello, por lo que finalmente la concluyó en la provincia de Chiapas. ${ }^{9}$

El tercer caso localizado en el que un juez y su residenciado llegaron a un acuerdo para no cumplir con los preceptos del proceso es el que involucró a Antonio Cueto Bracamonte como juez de residencia y a Pedro de la Maza de la Peña como enjuiciado. En la residencia de Cueto varios testigos de cierta relevancia deponían de manera detallada acerca de cómo se había fraguado el pacto. Así, Francisco Prudencio de Morales, encomendero de indios y vecino de la provincia, alegaba que cuando el capitán don Antonio Cueto había tomado la residencia a su antecesor, el gobernador Pedro de la Maza de la Peña, había cobrado 4.000 pesos de este último para que no le causase perjuicio alguno. Por su parte, el capitán Juan Francisco Vicente, vecino de la cabecera de la provincia, añadía que Cueto había dilatado más de dos meses la residencia, esperando a que de la Maza le entregase la cantidad pactada, y que en la composición había entrado también una mulata esclava, que Antonio Cueto envió a la Nueva España a su casa. ${ }^{10}$

9 Expediente realizado por el obispo de Chiapas sobre la actuación del oidor Benito de Noboa Salgado cuando tomó las residencias al gobernador de Costa Rica y al alcalde mayor de Tabasco, 16791680. AGI. Guatemala, 26, R.2, núm. 68.

10 Interrogatorio de la pesquisa secreta del juicio de residencia de Antonio Cueto Bracamonte, Tacotalpa, 23-25 de noviembre de 1688. AGI, Escribanía de Cámara, 228B; La afirmación del capitán Juan Francisco Vicente en cuanto a la dilatación de la residencia se corrobora examinando dos datos 
2.2 La recusación de los jueces y el acompañamiento de testigos

En la línea de la polémica y controversia que generaron los juicios de residencia en Tabasco, debemos referirnos a la frecuente práctica que los oficiales procesados en la provincia tuvieron de utilizar la fórmula de la recusación en sus juicios. Un sistema por el cual la persona juzgada tenía el derecho de apartar del conocimiento de la causa al magistrado que estaba encargado de residenciarlo, de forma tan sencilla que bastaba con una relación jurada donde indicase que lo tenía por sospechoso o parcial en el pleito. La discusión que generó este tipo de prácticas estuvo motivada, principalmente, por la falta de una adecuada legislación sobre la materia. Aunque es cierto que se aceptó la posibilidad de recusar a los jueces de residencia, como se recoge en la Política para corregidores de Castillo de Bovadilla, no existió ninguna ley que organizase y sistematizase la forma en que debía de realizarse y cómo actuar en consecuencia. De hecho, Bovadilla refería exclusivamente que, en caso de ser recusado, el magistrado debía acompañarse por un letrado neutral, a ser posible juez, docto y bien intencionado, además de advertir que no debía ejecutar las sentencias del acompañante si discordaba de ellas (Castillo de Bovadilla, 1775, p. 559). Por ello, algunos detalles de la reglamentación de las recusaciones fueron prevenidos por instituciones locales, como la Audiencia de México, que emitió varios autos, recogidos posteriormente por Bentura Beleña, donde se obligaba al escribano de cámara a certificar en cada remoción si se trataba de la primera o la segunda vez que se solicitaba. En caso de ser la segunda, el recusante debía demostrar inexcusablemente que los motivos que esgrimía eran suficientes para hacerlo, con lo que se evitaba que se realizasen deposiciones maliciosas (Bentura Beleña, 1787, p. 91). Anteriormente, en la Nueva Recopilación de 1567 ya se había recogido la indicación de que si alguna de las partes tenía por sospechoso al juez, éste se hiciese acompañar de un hombre bueno en los pleitos civiles. ${ }^{11}$

Teniendo en cuenta estos condicionantes, la forma de actuar de los jueces al verse recusados varió en función de sus intereses, provocando un sinfín de conflictos. En Tabasco, como decíamos, resultó frecuente que los residenciados utilizasen esta

concretos sobre Antonio Cueto: la fecha de su toma de posesión en el cargo de alcalde mayor en la provincia y la fecha de inicio del juicio que sustanció a Pedro la Maza de la Peña. Lo normal era que a los pocos días de comenzar su gestión en el cargo publicase los edictos para dar inicio al proceso de residencia. Sin embargo, podemos comprobar que empezó a gobernar el 17 de junio de 1684, demorando la publicación de la comisión para principiar el pleito hasta el 1 de octubre, más de tres meses después. Toma de posesión de Antonio Cueto Bracamonte como alcalde mayor de Tabasco, Tacotalpa, 17 de junio de 1684. AGI, Escribanía de Cámara, 228A; Publicación de la comisión para dar residencia a Pedro de la Maza de la Peña, Tacotalpa, 1 de octubre de 1684. AGI, Escribanía de Cámara, 228A.

11 Recopilación de las leyes de estos reinos, t. II, ley 1, tít. XVI, lib. IV, fol. 244; Para un conocimiento más profundo sobre el mecanismo y el funcionamiento de la recusación pueden consultarse los trabajos de Carlos Garriga "La recusación judicial: del derecho indiano al derecho mexicano" (Garriga, 1998, pp. 203-239) y "Contra iudicii improbitatem remedia. La recusación judicial como garantía de la justicia en la corona de Castilla" (Garriga, 2006, pp. 157-382). 
fórmula en sus residencias, rechazando no solo a los magistrados, sino también a determinadas personas que podían participar en sus juicios.

Uno de los casos más importantes, sobre todo por la repercusión que tuvo a nivel institucional, fue la recusación que Antonio Cueto Bracamonte realizó en 1688 a su juez y sucesor en el cargo, Francisco Benítez Maldonado, motivado por la dura residencia que, para sus intereses, el primero le estaba tomando. Y es que, debido al enfrentamiento entre ambos, la Audiencia de México y la propia Corona se posicionaron, la primera defendiendo al residenciado y la segunda a favor del juez pesquisidor. El enfrentamiento comenzó a gestarse con la llegada de Benítez a la provincia y el retraso que sufrió el inicio de la residencia de Cueto, toda vez que sus fiadores de Real Hacienda denunciaron ante el magistrado la deuda que éste había acumulado con el erario real y la intención que tenía de fugarse sin ser residenciado. Ante eso, y tras haber recibido un despacho de los señores del tribunal mayor y audiencia de cuentas de la Ciudad de México, el juez determinó asegurar al enjuiciado con el fin de poder recuperar el dinero perteneciente a la Real Hacienda. La respuesta de Antonio Cueto no se hizo esperar, puesto que inmediatamente remitió un escrito a dicho tribunal y al Real Acuerdo y sala de justicia de la Audiencia de México, dando razones falsas de su situación, intentando llevar a cabo una nueva fuga de la provincia, además de recusar al juez de residencia, declarándolo como su capital enemigo y solicitando que se abstuviese de continuar entendiendo en ella.

Por el contrario, el día 4 de noviembre de ese año, pese a haber recibido un auto del Real Acuerdo advirtiéndole de su mal proceder, Benítez decidió nombrar acompañado para proseguir con el pleito, designando para tal fin a un vecino de la villa, el capitán Juan Alonso Delgado, teniendo en cuenta que no había letrado en la provincia de Tabasco. ${ }^{12}$ Un día más tarde, el residenciado recusaba también al acompañante elegido por el juez, alegando que, pese a que era un buen hombre, no dejaba de ser un súbdito del magistrado, al que tenía persuadido, además de no ser capaz ni inteligente para entender de materias judiciales. ${ }^{13}$ El magistrado, en esa tesitura, le concedió facultad para que eligiese uno a su voluntad, con la única condición de que debía ser vecino o asistente en la provincia desde el tiempo de su gobierno, aunque, al no obtener una respuesta afirmativa, finalmente se vio obligado a escogerlo personalmente. Así, el día 6 de noviembre nombraba para el puesto a Francisco Sánchez de Arévalo, que también era recusado, alegando el enjuiciado que era lego y sin ninguna experiencia en el conocimiento de las leyes, por lo que

12 Petición de Antonio Cueto Bracamonte, presentando recusación de la residencia, Tacotalpa, 4 de noviembre de 1688. AGI, Escribanía de Cámara, 228B; Auto de Francisco Benítez Maldonado dándose por recusado y nombrando acompañado por dicha recusación, Tacotalpa, 4 de noviembre de 1688. AGI, Escribanía de Cámara, 228B; Auto del Real Acuerdo al juez de residencia para que trate a Antonio Cueto Bracamonte con la decencia y urbanidad que debe según las leyes y órdenes de su majestad, Cuidad de México, 15 de julio de 1688. AGI, Escribanía de Cámara, 228B.

13 Auto de Francisco Benítez Maldonado para que el residenciado responda derechamente sobre el acompañado, Tacotalpa, 5 de noviembre de 1688. AGI, Escribanía de Cámara, 228B. 
ese mismo día volvía a realizar una designación, escogiendo en esta ocasión al capitán Manuel Montero y al alférez José López Salgado, vecinos del partido de la Chontalpa. Tras una nueva remoción, el juez, cansado de la actitud de Cueto, decidía seleccionar a dos de los cuatro acompañados que había nombrado, realizando un sorteo en la sala de audiencias de las casas reales de Tacotalpa en el que salieron elegidos Juan Alonso Delgado y Manuel Montero. ${ }^{14}$

Sin embargo, el día 25 de noviembre Antonio Flores, alcalde ordinario y de la Santa Hermandad de la villa de Tacotalpa, notificaba a Francisco Benítez Maldonado una provisión del Real Acuerdo emitida un mes antes, en la que se determinaba su inhibición para continuar entendiendo en el proceso de la residencia, por lo que éste se vio obligado a renunciar y a abstenerse de fenecerla, comprometiéndose a enviarla al Consejo de Indias en el estado en que estaba en ese momento. ${ }^{15}$ Ahora bien, tras pasar por la institución metropolitana la situación volvía a cambiar sustancialmente, ya que Benítez, a través de su apoderado, Esteban de Buergo Santos, presentaba un recurso en el Consejo por la "notoria injusta nulidad" a la que había sido sometido, explicando pormenorizadamente los inadecuados procedimientos de la Real Audiencia de México, donde el residenciado tenía personas que le patrocinaban, y solicitando que se privase a dicha Audiencia del conocimiento de la residencia, en conformidad con la ley de la Recopilación que prohibía a dicho organismo entrometerse en esos asuntos y embarazar el uso de su comisión. ${ }^{16}$ El Consejo, tras consultar al fiscal, determinaba que la Audiencia debía inhibirse en la causa y permitir que el juez de residencia actuase con el acompañado que tenía nombrado, por lo que el 11 de octubre de 1690 se le remitía una real cédula informándoles de la decisión adoptada y continuando desde ese momento la residencia como se había decretado en la metrópoli. ${ }^{17}$

Otro de los casos de recusación destacable en los juicios de residencia tabasqueños fue el que tuvo como protagonistas al magistrado Mateo de Reigadas y Agüero y al residenciado Alonso Felipe de Andrade a principios del siglo XVIII,

14 Diligencias realizadas para la elección del nuevo acompañado, Tacotalpa, 5-22 de noviembre de 1688. AGI, Escribanía de Cámara, 228B.

15 El Real Acuerdo de la Audiencia de México inhibiendo a Francisco Benítez Maldonado de la residencia de Antonio Cueto Bracamonte, Ciudad de México, 25 de octubre de 1688. AGI, Escribanía de Cámara, 228B; Auto de suspensión de la residencia, Tacotalpa, 25 de noviembre de 1688. AGI, Escribanía de Cámara, 228B.

16 Petición de Esteban de Buergo, apoderado de Francisco Benítez Maldonado, al Consejo de Indias para que la Audiencia se inhiba de entender en la residencia de Antonio Cueto Bracamonte, Madrid, 27 de abril de 1690. AGI, Escribanía de Cámara, 228B; Recopilación de Leyes de Indias, ley 69, tít. XV, lib. II.

17 Determinación del Consejo de Indias sobre la inhibición de la Audiencia de México en la residencia de Antonio Cueto Bracamonte, Madrid, 11 de mayo de 1690. AGI, Escribanía de Cámara, 228B; Real Cédula informando a la Audiencia de México que se inhiba del juicio de residencia de Antonio Cueto Bracamonte, Madrid, 11 de octubre de 1690. AGNM, Reales Cédulas Originales, vol. 2, exp. 84 . 
fruto de una capitulación que le interpusieron en el pleito, según Andrade de manera parcial y malintencionada y con la permisividad del juez de residencia. Durante la residencia pública, el sargento mayor Andrés Gordillo, el capitán Juan Rodríguez de la Gala y el colector general Juan Antonio Garrido, demandaron a Alonso Felipe de Andrade, interponiéndole diez capítulos por los abusos y excesos cometidos durante su mandato al frente de la alcaldía mayor, que eran aceptados por el juez a principios de noviembre de 1706. Una vez realizado el interrogatorio correspondiente se determinó dar traslado de la capitulación y los cargos que habían resultado de ella al residenciado, con el fin de que pudiese ofrecer sus correspondientes descargos. ${ }^{18}$

Sin embargo, la respuesta de Andrade el 27 de noviembre fue clara. Afirmaba en la misma que no tenía intención de recibir los autos hasta que no viniese un abogado de la Ciudad de México que lo defendiese y pasaba a recusarlo públicamente como juez de residencia de todas las causas, demandas y denuncias de la misma, solicitando que se acompañase con uno de los abogados de la Real Audiencia México para poder proseguirla. El motivo alegado era la parcialidad que mostraba con los capitulantes, toda vez que era público y notorio que se habían convertido en sus enemigos hacía más de un año. El magistrado, por su parte, replicó diciendo que ya estaba fenecida la pesquisa secreta de la residencia y hechos los cargos resultantes, no entendiendo por qué había esperado a hacer la remoción al momento de finalizar la pública, declarándola por ello fuera de tiempo, máxime teniendo en cuenta la imposibilidad de traer letrados de México por lo dilatado del camino y el atraso que suponía para cumplir con su comisión de tomar las residencias del sargento mayor Pedro Gutiérrez de Mier y Terán y de los capitanes Pedro de Zagarraga y Jerónimo Álvarez del Valle.

Siendo evidente, además, que no existía ningún abogado a menos de 140 leguas con quien acompañarse, decidió nombrar como tal acompañado al capitán Manuel Ramos, vecino de la provincia y persona independiente en la residencia. ${ }^{19}$ Sin embargo, Andrade, volviendo a requerir la presencia de un letrado para que entendiese en la residencia, recusó dicha designación. Tras un cruce de notificaciones en las que el juez concedió al residenciado la facultad de elegir al acompañado con la única premisa de que fuese vecino o asistente en la provincia desde el tiempo de su gobierno, éste terminó señalando que no había en toda la región persona capacitada

18 Petición de capitulación de Andrés Gordillo, Juan Rodríguez de la Gala y Juan Antonio Garrido, contra el sargento mayor don Alonso Felipe de Andrade, por abusos y excesos cometidos durante su gobierno, Tacotalpa, 6 de noviembre de 1706. AGI, Escribanía de Cámara, 233B; Auto de notificación de los capítulos al sargento mayor Alonso Felipe de Andrade, Tacotalpa, 26 de noviembre de 1706. AGI, Escribanía de Cámara, 233C.

19 Recusación del juez de residencia por parte de Alonso Felipe de Andrade, Tacotalpa, 27 de noviembre de 1706. AGI, Escribanía de Cámara, 233C; Respuesta del juez de residencia a la recusación realizada por Alonso Felipe de Andrade, nombrando acompañado, Tacotalpa, 27 de noviembre de 1706. AGI, Escribanía de Cámara, 233C. 
para ello, por ser todos los vecinos labradores y porque sus adversarios tenían ganado el favor de todas las personas. ${ }^{20}$

El magistrado decidió entonces designar por su cuenta al alférez Andrés Muñoz Hidalgo el día 2 de diciembre, mostrando su disconformidad con el proceder de Andrade, el cual le parecía estaba intentando dilatar el proceso. Tras una nueva recusación por no ser hombre versado en leyes, Mateo de Reigadas volvió a designar otros dos nuevos acompañados, el alférez Juan Bautista de Echano, vecino del pueblo de Jalapa, y el capitán Nicolás Gómez de Herrera, residente en el partido de la Chontalpa, por considerarlos "independientes y personas honradas, de buenos créditos y fama", teniendo en cuenta que las leyes lo amparaban para ello como juez privativo sin subordinación que no fuese la real. No obstante, Andrade discrepó una vez más con la elección, pidiendo además que no se le notificasen más autos porque no entendía de judicatura, ya que su profesión era la de militar. Como última medida, el juez dispuso celebrar un sorteo entre los cuatro recusados, aduciendo que la Recopilación de Leyes de Indias prohibía a las Audiencias entrometerse en el conocimiento de las residencias cuando la comisión para tomarla había emanado de la Corona, por lo que era impropio solicitar, como lo hacía Andrade, que desde la institución colonial se nombrase y enviase acompañado. Así, el día 11 de diciembre, se llevó a cabo dicho sorteo en la sala de audiencias de las casas reales de Tacotalpa, en el cual fueron seleccionados el capitán Manuel Ramos y el alférez Andrés Muñoz Hidalgo. ${ }^{21}$

Pese a todo, el residenciado siguió empeñado en defender sus intereses. Por ello, aludiendo a que existía un antecedente en la provincia en el que se había detenido el juicio durante cinco años por una recusación, al acudirse al Consejo para que dirimiese sobre la misma (se refería al juicio de Antonio Cueto Bracamonte), volvía a rechazar a todos y se excusaba razonando que, en su caso, solamente pedía suspender el pleito unos meses, hasta la llegada de un abogado de la Audiencia de México que asistiese al magistrado y otro que entendiese en su defensa en lo relativo a los capítulos que le habían puesto sus enemigos. ${ }^{22}$ Finalmente, ese mismo día, a diferencia del caso analizado anteriormente, Reigadas tomaba la determinación de proseguir la causa con los dos acompañados elegidos por sorteo hasta su fenecimiento pese a las continuas quejas de Andrade sobre su proceder. ${ }^{23}$

20 Autos hechos en relación al nombramiento de acompañante para el juez de residencia, Tacotalpa, 27-29 de noviembre de 1706. AGI, Escribanía de Cámara, 233C.

21 Nombramiento del alférez Andrés Muñoz Hidalgo como nuevo acompañado, Tacotalpa, 2 de diciembre de 1706. AGI, Escribanía de Cámara, 233C; Nombramiento de acompañados en las personas del alférez Juan Bautista de Echano y el capitán Nicolás Gómez de Herrera, Tacotalpa, 4 de diciembre de 1706. AGI, Escribanía de Cámara, 233C; Sorteo para elegir acompañados del juez de residencia don Mateo de Reigadas y Agüero, Tacotalpa, 11 de diciembre de 1706. AGI, Escribanía de Cámara, 233C.

22 Recusación del juez de residencia y de los acompañados nombrados por parte de Alonso Felipe de Andrade, Tacotalpa, 11 de diciembre de 1706. AGI, Escribanía de Cámara, 233C.

23 Sentencia de la residencia de Alonso Felipe de Andrade, Tacotalpa, 20 de diciembre de 1706. AGI, Escribanía de Cámara, 233C. 


\subsection{El escribano de residencia: un cargo a veces controvertido}

Otro de los aspectos reseñables que caracterizaron a los juicios de residencia tabasqueños fue la endémica dificultad que hubo para disponer de escribano público o real en la residencia. A todas luces se trataba de una figura indispensable, considerando su labor como principal asistente y colaborador del magistrado encargado de efectuar la residencia, sobre todo porque era ante quien actuaba éste. De forma excepcional, en aquellos territorios donde no había escribanos, o en donde los disponibles quedaban incluidos entre los que debían ser residenciados, estaba permitido que estos fuesen reemplazados con dos testigos "de asistencia". Ahora bien, se trataba de una opción poco frecuente y en pocas ocasiones permitida, motivo por el que la presencia del escribano era requisito inexcusable para llevar a cabo el juicio de residencia (Mariluz, 1952, p. 69).

A pesar de lo dicho, las difíciles condiciones geográficas y sociales que presentaba la alcaldía de Tabasco conllevó, entre otras muchas cosas, que la falta de escribano se convirtiese en algo demasiado cotidiano, motivo por el cual se tornó en norma que continuamente hubiesen de venir escribanos de otras provincias, como Campeche, Santiago de Guatemala o Chiapas, para ocupar dicho puesto, o que, incluso, en alguna ocasión de extrema necesidad el juez se viese obligado a contar con la ayuda de dos testigos de asistencia para cubrir su ausencia. Efectivamente, durante el periodo que abarca esta investigación la región nunca contó con más de dos escribanos públicos o reales a la vez y, cuando los tuvo, en casi todas las ocasiones fueron recusados en las residencias por ser parte implicada en las mismas y debiendo por ello ser también juzgados.

Un buen ejemplo de dicha situación nos lo brinda la residencia efectuada en 1666 al alcalde mayor Juan del Águila Gayoso por su sucesor Francisco Maldonado de Tejada, quien se vio forzado a nombrar dos testigos para que lo asistiesen, debido a la muerte de Francisco de Frías Maderos, único escribano que había en toda la provincia poco antes de iniciarse el proceso. El motivo de tal acción derivó de no haber conseguido localizar a ningún otro escribano para tal fin, pese a haber realizado las pertinentes diligencias para traerlo de alguna provincia cercana, concretamente de las circunvecinas regiones de Chiapas, Yucatán y Acayuca, además del puerto de Veracruz. ${ }^{24}$ Ante dicha situación, Maldonado se vio en la tesitura de designar como

24 Información de Francisco Maldonado de Tejada sobre no haber escribano real en la provincia, Santa María de la Victoria, 10 de agosto de 1666. AGI, Escribanía de Cámara, 222C. En dicho documento se explican las diligencias llevadas a cabo "para intentar traer escribano desde las provincias de Chiapas, Yucatán y Acayuca y desde el puerto de la Veracruz, circunvecinas, y el no haber podido conseguir traerlo para tomar la residencia por no haberlos, por estar ocupado el que había en Chiapas, no haber tampoco en otras provincias y los que había no poder venir por la mucha pobreza de la provincia de Tabasco y por hallarse robada y saqueada del enemigo, además de lo distante que estaba de la provincia de Yucatán y ser los caminos malos y anegados". Estos motivos serán utilizados constantemente durante toda la segunda mitad del siglo XVII. 
testigos de asistencia al capitán Andrés de Cote y Heredero y al alférez Fernando de Flores, vecinos de la provincia. Sin embargo, tras percatarse que el primero de ellos estaba inserto en la lista de las personas que debían dar la residencia junto con el alcalde, finalmente tuvo que nombrar al alférez Martín de Ibarra en su lugar, quien, junto a Flores, actuó como acompañante hasta fenecer el juicio. ${ }^{25}$

El siguiente ejemplo lo encontramos en la residencia de Francisco Maldonado de Tejeda, sucesor de Juan del Águila Gayoso en la alcaldía mayor. Una vez más, el magistrado encargado del juicio informaba de la falta de escribano para comenzar la residencia, aunque en esta ocasión conseguía que Francisco de Matos, escribano de la provincia de Campeche, viajase hasta Tabasco para actuar como notario de la residencia. Ahora bien, además de su salario, estipulado en 6 pesos diarios durante los 60 días que durase el proceso, y sus derechos por lo escrito y actuado, Miguel Fernández del Rivero se comprometió a pagarle otros 500 pesos como ayuda de costa por los gastos del viaje y su estancia en la región. ${ }^{26}$

Otro tanto sucedió en la residencia de Fernández del Rivero, encargada al oidor de la ciudad de Santiago de Guatemala, Benito de Novoa, quien buscando asegurar la presencia de un escribano que lo acompañase en la residencia decidió llevárselo de Guatemala, nombrando para tal efecto a don Benito Berduyo, escribano público del número de la ciudad de Santiago. ${ }^{27}$

En el juicio de Pedro de la Maza de la Peña también fue necesario traer un escribano de otra provincia para poder iniciar la residencia. En este caso el elegido fue Pedro Álvarez de Miranda, escribano público y del número de la ciudad real de Chiapa y del juzgado mayor de indios en dicha provincia, que llegó a Tabasco en 1684 para tal fin. Resulta, cuanto menos curioso, que el mismo personaje, poco tiempo después, en 1693, ejerciese como juez de residencia de otro alcalde tabasqueño, Francisco Benítez Maldonado, y que a principios del siglo XVIII llegase a ostentar provisionalmente, durante un mes, el puesto de alcalde mayor de Tabasco, tras haberlo sido previamente de Chiquimula de la Sierra, en Guatemala. ${ }^{28}$

25 Nombramiento de testigos de asistencia para el juicio de residencia de Juan del Águila Gayoso, Nueva villa de Santa María de la Victoria, 14 de agosto de 1666. AGI, Escribanía de Cámara, 222C; Nombramiento del alférez Martín de Ibarra como testigo de asistencia en sustitución de Andrés de Cote, Nueva villa de Santa María de la Vitoria, 9 de septiembre de 1666. AGI, Escribanía de Cámara, $222 \mathrm{C}$.

26 Nombramiento de oficiales de residencia para el juicio de Francisco Maldonado de Tejeda, Nueva villa de Santa María de la Vitoria, 21 de mayo de 1671. AGI, Escribanía de Cámara, 225A.

27 Nombramientos de escribano y alguacil ejecutor para el juicio de residencia de Miguel Fernández del Rivero, Santiago de Guatemala, 9 de diciembre de 1676. AGI, Escribanía de Cámara, 374B.

28 Nombramiento de escribano para la residencia de Pedro de la Maza de la Peña, Tacotalpa, 2 de octubre de 1684. AGI, Escribanía de Cámara, 228A; Comisión a don Pedro Álvarez de Miranda, que va proveído por alcalde mayor de la provincia de Chiquimula de la Sierra, en Guatemala, para que tome residencia a don Francisco Benítez Maldonado, alcalde mayor de la provincia de Tabasco, Madrid, 3 de octubre de 1690. AGI, Escribanía de Cámara, 229C. 
Otro ejemplo podemos encontrarlo en el juicio celebrado por Francisco Benítez Maldonado a su antecesor en el cargo, Antonio Cueto Bracamonte. En dicho pleito, después de haberse intentado por todos los medios traer a un escribano desde Guatemala, toda vez que los dos que estaban disponibles en la región se encontraban recusados, finalmente, tras la aprobación del residenciado y la retirada de la exclusión de uno de ellos, se pudo designar como escribano de la misma a Gaspar Sarmiento de Acosta para continuar con el proceso con arreglo a la ley. ${ }^{29}$

A partir de ese momento, los cuatro juicios de residencia restantes fueron monopolizados por Sarmiento de Acosta, toda vez que en 1678 había sido nombrado escribano público del cabildo, minas y registros de Tabasco y notario de las Indias. Un título adquirido un año antes en almoneda pública en Tacotalpa, por el que había pagado 2.200 pesos, y que presentó para su confirmación en 1683 en el Real Acuerdo de la Audiencia de México, tras haber ejercido como tal en Tabasco durante cinco años. ${ }^{30}$

Sin embargo, pese a que se alcanzó una cierta estabilidad en ese sentido, lo cierto es que el cargo no estuvo exento de controversia, teniendo en cuenta que dicho escribano de residencia, que actuaba también de ordinario durante el ejercicio del poder de los alcaldes, debía ser incluido entre los residenciados al finalizar cada mandato, aunque en ninguno de los cuatro últimos juicios aparece referenciado como tal. Ello dio pie a diversas críticas, pues dicho escribano actuaba como juez y parte en la provincia, adaptándose a las directrices impuestas por los gobernantes de turno, fruto, quizás, de la necesidad de recuperar la nada desdeñable inversión realizada para comprar el cargo y poder ejercer así como escribano en la región. Las críticas más fuertes las recibió en el juicio de Andrade, quien se quejaba amargamente de su silencio durante el proceso, toda vez que su juez de residencia, Mateo de Reigadas y Agüero, lo estaba imputando por múltiples cargos, algunos de los cuales, según él, eran falsos, y Gaspar Sarmiento, como escribano que lo había acompañado durante su mandato, lo sabía. Además, utilizaba la participación del escribano como excusa

29 Nombramiento de escribano para la residencia de Antonio Cueto Bracamonte, Tacotalpa, 16 de noviembre de 1688. AGI, Escribanía de Cámara, 228B. El otro escribano recusado era Pedro Álvarez de Miranda.

30 Nombramiento de oficiales para la residencia de Francisco Benítez Maldonado, Tacotalpa, 23 de abril de 1693. AGI, Escribanía de Cámara, 229C; Nombramiento de escribano para la residencia de Pedro de Zagarraga, Tacotalpa, 10 de enero de 1707. AGI, Escribanía de Cámara, 233C; Nombramiento de escribano para la residencia de Pedro Gutiérrez de Mier y Terán, Tacotalpa, 28 de marzo de 1707. AGI, Escribanía de Cámara, 233C; En el juicio de residencia de Alonso Felipe de Andrade no aparece reflejado el nombramiento, pero desde las diligencias previas Gaspar Sarmiento de Acosta firma como escribano de las mismas; Auto de Mateo de Reigadas para que se saquen testimonios de las reales cédulas en donde se le da comisión para tomar las residencias, Tacotalpa, 18 de octubre de 1706 . AGI, Escribanía de Cámara, 233C; Expediente de confirmación de los oficios de escribano público del cabildo, minas y registros de Tabasco y notario de las Indias a Gaspar Sarmiento de Acosta, Madrid, 14 de marzo de 1697. AGI, México, 201, núm. 1. 
para solicitar la nulidad del proceso, aseverando que debía ser residenciado por haber ejercido durante gobierno. ${ }^{31}$

\subsection{El papel sellado y sus recurrentes carestías}

En la misma línea de la permanente escasez de escribanos que actuasen en las residencias tabasqueñas nos encontramos con la endémica ausencia de papel sellado, imprescindible también en las mismas, considerando su obligatoriedad en la generación de cualquier tipo de documento oficial. Concretamente, el papel del sello tercero, que era el utilizado para los procesos judiciales, brillaba por su ausencia en la región en demasiados momentos, motivo por el que en no pocas veces los jueces se vieron obligados a solicitar que lo trajeran desde provincias cercanas, con el consecuente retraso que eso suponía para el inicio de los juicios. Incluso, en más de una ocasión dicha carestía provocó la interrupción de alguno de los pleitos hasta la llegada del mismo, algo lo suficientemente relevante como para ponerlo de manifiesto en este contexto.

Un magnífico ejemplo de este escenario nos lo brinda la residencia de Miguel Fernández Rivero. El juez de la misma, Benito de Noboa, se vio obligado a requerirle al escribano que iba a acompañarlo que consiguiese papel sellado en el reino de Guatemala antes de partir hacia Tabasco, "por tener noticia de que no lo hay en dicha provincia de México". ${ }^{32}$ Más controvertido resultó en ese sentido el juicio de Antonio Cueto en 1688, el cual tuvo que ser suspendido entre los meses de junio y noviembre, después incluso de haberse realizado las diligencias previas, por no haber papel sellado ni escribano público. El juez de residencia, Francisco Benítez Maldonado, aprovechando una petición de los fiadores para que se parase el proceso hasta que se terminase de recaudar todo lo que debía Antonio Cueto a la Real Hacienda con el fin de no verse perjudicados personalmente, decidía interrumpir el pleito el 20 de junio, atendiendo a la solicitud de dichos fiadores y alegando que no había papel sellado ni había llegado el escribano que había pedido de Santiago de Guatemala. Inmediatamente, el magistrado realizó las diligencias pertinentes para poder proseguir con la residencia, enviando al capitán Pedro Álvarez de Miranda a la provincia de Chiapas para que consiguiese el papel y procurase un escribano que actuase ante él durante el proceso. El 2 de noviembre, después de meses de espera, llegaba Álvarez con pliegos suficientes desde Ciudad Real de Chiapa, aunque con la noticia de que el único escribano que podía venir de aquella provincia, José Antonio de Torres, no había aceptado la propuesta. En esa tesitura, el juez nombró a Gaspar

31 Petición de Carlos Navías al Real Acuerdo de la Audiencia de México, en nombre de Alonso Felipe de Andrade, sobre que se declare nulo lo actuado por el juez de residencia, Ciudad de México, 11 de julio de 1707. AGI, Escribanía de Cámara, 233C.

32 Petición de Benito de Noboa, juez de residencia, para llevar papel sellado a la provincia de Tabasco, Santiago de Guatemala, 9 de diciembre de 1676. AGI, Escribanía de Cámara, 374B. 
Sarmiento de Acosta para tal causa el 16 de noviembre, prosiguiéndose así el juicio pese a que, en teoría, el amanuense había estado recusado por el residenciado. ${ }^{33}$

Ya a principios del siglo XVIII, el magistrado Mateo de Reigadas y Agüero volvía a notificar la ausencia de papel sellado para actuar en las residencias que estaba tomando. Concretamente, el 16 de enero de 1707, después de haber ejecutado las diligencias previas en el juicio de Pedro de Zagarraga, advertía que se había acabado dicho papel sellado y que, pese a haber despachado un correo a la Ciudad de México hacía tres meses para traerlo a la provincia, éste aún no había regresado. En esa tesitura, contrario a lo dispuesto por ley y al proceder de sus antecesores, el juez determinó proseguir con el pleito actuando con papel común, debido a los agravios que podían derivar de mantener parada la causa después de haberla iniciado. ${ }^{34} \mathrm{En}$ esta ocasión no es de extrañar, sin duda, que se agotase todo el papel del sello tercero en la región, teniendo en cuenta que Reigadas estaba entendiendo en tres residencias como magistrado y que el litigio de la más voluminosa, la de Alonso Felipe de Andrade, estaba ya en esa fecha casi fenecida, habiendo generado una ingente cantidad de documentación. ${ }^{35}$

\section{CONCLUSIÓN}

A la luz de lo analizado, resulta bastante coherente afirmar que las peculiaridades e irregularidades que se han planteado en este trabajo llegaron a condicionar el desarrollo y el resultado de los juicios de residencia en no pocas ocasiones, y que tuvieron influencia, también, en la mayor o menor eficacia y validez de dichos procesos como elementos de control de las autoridades indianas. Efectivamente, las composiciones o arreglos entre jueces y residenciados resultan un buen ejemplo en ese sentido, toda vez que privaban a los vecinos de la región de poder expresar su descontento con el gobernante de turno y evitaban que llegasen noticias al Consejo de Indias sobre la mala praxis de los alcaldes mayores. A ello habría que sumar la posibilidad de medrar en la administración indiana que dichos regentes se ganaban al conseguir que, de cara a la metrópoli, se les considerase como oficiales ejemplares

33 Petición de los fiadores para suspender la residencia hasta que se termine con el proceso de recaudación de lo que debe a la Real Hacienda Antonio Cueto Bracamonte, Tacotalpa, 20 de junio de 1688. AGI, Escribanía de Cámara, 228A; Auto de suspensión de la residencia, Tacotalpa, 20 de junio de 1688. AGI, Escribanía de Cámara, 228A; Auto del juez de residencia, Francisco Benítez Maldonado, para que se ponga testimonio del día que llegó el papel sellado para proseguir con dicha residencia, Tacotalpa, 2 de noviembre de 1688. AGI, Escribanía de Cámara, 228A; Nombramiento de escribano para la residencia de Antonio Cueto Bracamonte, cit.

34 Auto para que se prosiga la residencia pese a no haber papel sellado, Tacotalpa, 16 de enero de 1707. AGI, Escribanía de Cámara, 233C.

35 Juicio de residencia de Alonso Felipe de Andrade, 1706-1709. AGI, Escribanía de Cámara, 233C. El expediente completo contiene 5 cuadernos, de los cuales los tres primeros, que representan más del 90 por ciento del mismo, contienen documentación anterior a la fecha en la que el juez notificó la carestía de pliegos sellados. 
que habían ejercido sus funciones con rectitud y responsabilidad, con la consiguiente posibilidad de volver a repetir posteriormente sus cuestionadas prácticas en otros cargos de responsabilidad, convirtiendo la corrupción y los abusos de poder en algo cotidiano.

Al hilo de lo anterior, las constantes recusaciones que los alcaldes residenciados hacían de los magistrados que debían juzgarlos, o de los acompañantes que actuaban ante ellos por la falta de escribano, también debieron afectar sobremanera al resultado del proceso, sobre todo si el gobernante juzgado tenía suficiente influencia en esferas superiores como para que sus peticiones fuesen escuchadas. Por supuesto, la posibilidad de detener durante un tiempo la causa les brindaba igualmente un margen de tiempo para intentar "arreglar" su situación, por ejemplo, aspirando a condicionar el signo de las declaraciones de los testigos que debían manifestar su opinión en el juicio o eliminando pruebas que pudiesen inculparlos. ${ }^{36} \mathrm{El}$ hecho de que la carestía del papel sellado que debía utilizarse en dichos procesos frenase en seco su desarrollo y fenecimiento pudo, asimismo, condicionar el resultado de estos, toda vez que en ese lapso los residenciados también ganaban tiempo para poder influir en los vecinos y conspirar para intentar salir indemnes en sus residencias.

De la misma forma, el hecho de que el escribano de residencia en Tabasco actuase como juez y parte en los pleitos de manera habitual, debido a la escasez de oficiales amanuenses en la provincia, pudo motivar que estos mantuviesen una actitud parcial en los mismos, condicionando determinadas actuaciones y revisiones en su propio beneficio y limitando, por tanto, la capacidad de los jueces para indagar sobre determinados comportamientos de los residenciados y la voluntad de los testigos de declarar sobre las actuaciones de estos.

Resulta evidente, por tanto, que todos estos aspectos que acabamos de referir implican, igualmente, un importante lastre para los juicios de residencia como fuente documental, pues coartan al historiador la posibilidad de acercarse a una rica fuente de información sobre las acciones y actitudes que los gobernantes desarrollaron en el ejercicio de sus labores como oficiales de la administración indiana. Ahora bien, como contraprestación, no cabe duda de que todas estas peculiaridades e irregularidades también nos ayudan a comprender algunos aspectos importantes de los lugares donde se desarrollaban, como pueden ser la marginalidad de la región, la falta de apoyo de las instituciones, la situación y el contexto social en el que se movieron sus protagonistas o las redes de poder que fueron fraguándose a lo largo del tiempo en aquellos territorios.

36 Para ampliar información sobre los excesos y abusos de poder cometidos por los alcaldes mayores y sobre las condenas que sufrieron en sus juicios de residencia se recomienda la consulta de la obra Gobernar bajo sospecha: estrategias del poder y prácticas corruptas en la alcaldía mayor de Tabasco (1660-1716) (Moreno, 2018). 


\section{BIBLIOGRAFÍA}

Andújar Castillo, Francisco, Feros, Antonio y Ponce Leiva, Pilar (2017). Corrupción y mecanismos de control en la Monarquía Hispánica: una revisión crítica. Tiempos modernos, n. 35, pp. 284-311.

Angeli, Sergio (2012). El juicio de residencia: documento inicial para la reconstrucción de la vida social y profesional de los oidores americanos (siglo XVI-XVIII). Revista Electrónica de Fuentes y Archivos, n. 3, pp. 182-196.

Angeli, Sergio (2014). Un temprano juicio de residencia colonial: el Licenciado Juan Fernández, primer fiscal de la Audiencia de Lima. Investigaciones y Ensayos, $\mathrm{n}$. 60, pp. 437-457.

Andújar Castillo, Francisco y Ponce Leiva, Pilar (2018). Debates sobre corrupción en el mundo ibérico, siglos XVI-XVIII. Alicante: Biblioteca Virtual Cervantes.

Bentura Beleña, Eusebio (1787). Recopilación sumaria de todos los autos acordados de la Real Audiencia y Sala del Crimen de esta Nueva España. México: Don Felipe de Zúñiga y Ontiveros, tomo I.

Borah, Woodrow, (2002). El gobierno provincial en la Nueva España 1570-1787. México: Universidad Nacional Autónoma de México.

Castillo de Bovadilla, Gerónimo (1775). Política para corregidores y señores de vasallos en tiempo de paz y guerra. Madrid: Imprenta Real de la Gazeta, tomo II.

Collantes de Terán de la Hera, María José (1998). El juicio de residencia en Castilla a través de la doctrina jurídica de la Edad Moderna. Historia. Instituciones. Documentos, n. 25, pp. 151-184.

De la Peña y De la Cámara, José María (1955). A List of Spanish Residencias in the Archives of the Indies, 1516-1775: Administrative Judicial Reviews of Colonial Officials in the American Indies, Philippine and Canary Islands. Washington: Library of Congress.

Garriga, Carlos (1998). La recusación judicial: del derecho indiano al derecho mexicano. La supervivencia del derecho español en Hispanoamérica durante la época independiente. México: Universidad Nacional Autónoma de México, pp. 203-239.

Garriga, Carlos (2006). "Contra iudicii improbitatem remedia". La recusación judicial como garantía de la justicia en la corona de Castilla. Initium. Revista catalana d'historia del dret, n. 11, pp. 157-382.

Garriga, Carlos (2017). "Crimen corruptionis". Justicia y corrupción en la cultura del "ius commune". (Corona de Castilla, siglos XVI-XVII). Revista Complutense de Historia de América, n. 43, pp. 21-48. DOI: https://doi.org/10.5209/RCHA.56725

González Alonso, Benjamín (1978). El juicio de residencia en Castilla I. Origen y evolución hasta 1480. Anuario de Historia del Derecho Español, n. 48, pp. 193-248.

Jiménez Núñez, Alfredo (1997). El juicio de residencia como fuente etnográfica: Francisco Briceño, gobernador de Guatemala (1565-1569). Revista Complutense de Historia de América, n. 23, pp. 11-22. 
Jiménez Pelayo, Águeda (2009). Funcionarios ante la justicia: residencias de alcaldes mayores y corregidores ventiladas ante la Audiencia de Guadalajara durante el siglo XVIII", en Estudios de Historia Novohispana, núm. 40 (México, 2009), pp. 81-120.

Mariluz Urquijo, José María (1952). Ensayo sobre los juicios de residencia indianos. Sevilla: Escuela de Estudios Hispanoamericanos.

Mojarrieta, José Serapio (1848). Ensayo sobre los juicios de residencia. Madrid: Imprenta de Alhambra y Cía.

Molina Argüello, Carlos (1973). Visita y residencia en Indias. En III Congreso del Instituto Internacional de Historia del Derecho Indiano. Madrid: Instituto Nacional de Estudios Jurídicos, pp. 423-431.

Molina Argüello, Carlos (1975). Las visitas-residencias y residencias-visitas de la Recopilación de Indias. Caracas: Academia Nacional de la Historia.

Moreno Amador, Carlos (2018). Gobernar bajo sospecha: estrategias del poder y prácticas corruptas en la alcaldía mayor de Tabasco (1660-1716). Sevilla: Universidad de Sevilla, CSIC y Diputación de Sevilla.

Moreno Amador, Carlos (2019). El valor del Juicio de Residencia como fuente documental: estructura, características y peculiaridades. El paradigma de Tabasco en la segunda mitad del siglo XVII. Temas Americanistas, n. 42, pp. 160-191.

Piña Gutiérrez, Jesús Antonio (2006). Historia del sistema jurídico y del poder judicial en Tabasco. Villahermosa: Universidad Juárez Autónoma de Tabasco.

Recopilación de Leyes de los Reinos de las Indias. Madrid: Boix, 1841.

Smietniansky, Silvina (2012). El estudio de las instituciones del gobierno colonial. Una aproximación etnográfica al juicio de residencia como ritual. Corpus, vol. 2, n. 1, pp. 1-37.

Vaccari de Venturini, Letizia (1983). Juicios de residencia en la provincia de Venezuela. Don Francisco Dávila Orejón Gastón (1673-1677). Caracas: Academia Nacional de Historia. 